\title{
राष्ट्रीय विकास में हिन्दी की भूमिका
}

\author{
रागिनी राठौर \\ शोधार्थी-हिन्दी विभाग \\ अ.प्र. सिंह वि. वि. रीवा (म.प्र.)
}

“ गूँजी हिन्दी विश्व में, स्वप्न हुआ साकार राष्ट्र संघ के मंच से, हिन्दी की जयकार हिन्दी की जयकार, हिन्द हिन्दी में बोला देख स्वभाषा प्रेम, विश्व अचरज से डोला कह कैदी कविराय, मेम की माया टूटी भारत-माता धन्य, स्नेह की सरिता फूटी।।' '-माननीय अटल बिहारी बाजपेयी

हिन्दी आज विश्व भाषा बन चुकी है क्योंकि दुनिया के हर देश में हिन्दी भाषी अपनी उपस्थिति दर्ज करा रहे हैं। वह उपस्थिति चाहें आर्थिक क्षेत्र में हो अथवा राजनीतिक या सामाजिक क्षेत्र में। भारतीयों ने आज अपने को मेम की माया (अंग्रेजी) के मकड़जाल से मुक्त कर अपना एक अलग मुकाम बनाया है जिसकी अनुगूँज दुनिया में हर जगह सुनी जा सकती है। भारतीय जनमानस की अभिव्यक्ति जननी हिन्दी, पवित्र सलिला गंगा की तरह है जिसका हजारों लोग पानकर अपनी प्यास बझाते हैं। आदिकाल से लेकर आज तक ऋषि, मुनि, कवि, लेखक हिन्दी भाषा में अवगाहन कर प्रत्यक्ष या परोक्ष रूप से राष्ट्रीय विकास में अपना योगदान दिया है। तुलसीबाबा ने अपने महानतम् ग्रन्थ 'रामचरितमानस' की अभिव्यक्ति के लिए हिन्दी (अवधी) को चुना और उनका यह ग्रन्थ हमें लोकतंत्र की सच्ची तश्वीर दिखाता है, बताता है कि सच्चे अर्थो में लोककल्याणकारी राज्य किसे कहते हैं। सूरदास ने हिन्दी भाषा में अवगाहन कर वात्सल्य को पराकाष्ठा तक पहुँचाया। मस्तमौला कबीर ने हिन्दी के दम पर रूढ़ियों पर कुठाराघात कर, सामाजिक परिवर्तन में अपना महत्वपूर्ण योगदान दिया। 
साहित्य जीवन की अभिव्यक्ति और वास्तविकता है। दुनिया के हर विकास के केन्द्र में मनुष्य होता है और यदि हम हिन्दी साहित्य में अवगाहन करें तो उसके केन्द्र में भी हमें 'मानुष-सत्य' ही दिखाई देता है। साहित्य का लक्ष्य है मनुष्य को मानवता का पाठ पढ़ाना और जिस दिन व्यक्ति मानवता का पाठ पढ़ लेगा उसका विकास खुद-व-खुद हो जायेगा। डॉ. पृथ्वीनाथ पाण्डेय के शब्द उधार लें तो -“ चिरकाल से ही मानवता के मसीहा-साहित्यकार जीवन को मूल्यवान सिद्ध करने में प्रयत्नशील हैं। वे मानव-जाति की आत्मा की भाषा गढ़ने में निमग्न रहे हैं। उन्होंने जीवन के सभी स्तरों पर भोगा और अपना मार्मिक अनुभूति को स्रष्टा के सिंहासन पर बैठाकर उसे साहित्य में प्रतिबिम्बित किया। इस तरह साहित्य जीवन के ताप और स्वाभाविकता का अभूतपूर्व दर्पण बन गया। जीवन की स्वाभाविकता में भोग्यमान् मानव जीवन के प्रति अटूट आस्था के रूप में झलकने लगा। हमारे राग-विलास की सभी पर्तों का सुकोमल स्पर्श होने लगा और हम अत्यन्त सहज भाव से यह तथ्य स्वीकार करने लगे कि सम्पूर्ण साहित्य, चाहे वह रवीन्द्रनाथ का हो या बंकिमचन्द्र का, प्रेमचन्द का हो या सरत्चन्द्र का, गोर्की का हो या टॉलस्टाय का, मार्क्स का हो या डार्विन का, लोककेन्द्रित है। उनकी रचना की सम्पूर्ण कथा उनके भाव विगलित हदृय की सच्ची अनुभूति और संजीवनी से सिक्त है। जीवन-सत्य को साधारणीकृत कर संप्रेषित करने वाला यह साहित्य जन-जन का कण्ठहार बनकर समाज में लोक-मंगल की गंगा प्रवाहित कर देता है। ${ }^{\prime 1}$

राष्ट्रीय विकास में हिन्दी की भूमिका को हिन्दीतर आत्माओं ने बहुत पहले पहचान लिया था इसीलिए स्वामी विवेकानन्द, महर्षि दयानन्द सरस्वती, महात्मा गाँधी और सुभाषचन्द्र बोस ने मुक्तकण्ठ से हिन्दी की वकालत की। यह सभी विभूतियाँ जानते थे कि हिमालय से लेकर कन्याकुमारी तक एक सूत्र में बांधने वाली भाषा हिन्दी है। हिन्दीतर पूर्व प्रधानमंत्री श्री एच.डी. देवगौड़ा ने राष्ट्रीय विकास में हिन्दी की भूमिका को इस प्रकार रेखांकित किया है। " विदेशी भाषा केवल धन्ना सेठों को जोड़ती है, नेताओं को जोड़ती है, बड़े-बड़े लोगों को जोड़ती है, अफसरों को जोड़ती है, पूँजीपतियों को जोड़ती है लेकिन क्या राष्ट्र यहीं समाप्त हो जाता है? क्या कृषक, क्या श्रमिक, क्या स्त्रियाँ, क्या अंकिचन जन, क्या ग्राम्य जन, क्या बच्चे, क्या पिछड़े वर्ग, क्या अल्पसंख्यक, क्या हरिजन और क्या गिरिजन भारत के अभिन्न अंग नहीं है? क्या ये भारत माता की सन्ताने नहीं हैं? इन्हें जोड़ने की जरूरत नहीं है क्या? इन करोड़ो लोगों को आखिर कौन जोड़ेगा? क्या इन्हें विदेशी भाषा जोड़ सकती है? इन्हें जोड़ने वाली भाषा तो सिर्फ एक ही है और उसका नाम है - हिन्दी, राष्ट्रभाषा हिन्दी, सारे राष्ट्र को एक सूत्र में पिरोने वाली हिन्दी।"2

आज हिन्दी एक उद्योग की तरह है उसका अपना एक 'मार्केट' है जिसमें हजारों लोग अपनी जीविका कमा रहे हैं, उदाहरण स्वरूप फिल्म उद्योग को लें तो कितने लोग जुड़े हुए है -'सखि सैंया तो खूबहिं कमात है, मँहगाई डायन खाए जात है।" जैसे गीतों से कितने लोगों को रोजगार प्राप्त हो रहा है। 
गया प्रसाद प्रजापति से लेकर अमीर खान तक की जीविका का साधन है यह हिन्दी गीत। ' टेरी इगल्टन' की बात पर गौर करें तो -“" साहित्य एक कला की वस्तु हो सकता है, सामाजिक चेतना का उत्पादन हो सकता है, एक विश्वदृष्टि हो सकता है, लेकिन इसी के साथ-साथ वह एक उद्योग भी हैं। किताबें सिर्फ अर्थ की संरचनाएँ नहीं है, वे एक उत्पाद भी है जिन्हें प्रकाशक लाभ के लिए बाजार में बेचते हैं। नाटक सिर्फ एक साहित्यिक पाठ का समुच्चय नहीं है, वह एक पूंजीवादी व्यापार भी है, जिसमें कई तरह के आदमी लगे होते हैं। वह भी एक उत्पाद है, जिसे दर्शकों द्वारा देखा जाता है और इस प्रक्रिया में लाभ कमाया जाता है। और इसी से जुड़ा होता है प्रत्यक्ष या अप्रत्यक्ष रूप से हमारा राष्ट्रीय विकास।

बाजार ने, विज्ञापन ने हिन्दी को एक क्रान्तिकारी रूप दिया, जिसमें खानगी है, स्वाद है, रोमांच है, आज की सबसे बड़ी चाहत का अकूत संसार है। इस तरह हिन्दी वर्तमान एवं भविष्य की भाषा, समाज का तकाजा और रोजगार की जरूरत बनती जा रही है।

लोकतंत्र का चौथा स्तंभ पत्रकारिता है। सूचना क्रान्ति ने विश्व को ग्राम बना दिया है। मीडिया की जागरूकता ने समाज में एक क्रान्ति ला दी है और इस क्रान्ति की भाषा हिन्दी है। इतने सारे समाचार चैनल है और सभी चैनलों पर हिन्दी अपने हर रूप में नए कलेवर, तेवर में निखर कर, सँबरकर, लहरकर, 'बोले तो बिदांस' बनकर छाई रहती है। तुलनात्मक अर्थों में आज अंग्रेजी पत्रकारिता से हिन्दी पत्रकारिता का मूल्य, बाजार, उत्पादन, उपभोग और वितरण बहुत बड़ा है।

प्रिंट मीडिया की स्थिति ज्यादा बेहतर है, पत्र-पत्रिकाओं की लाखों प्रतियाँ रोजाना बिकती हैं। चीन के बाद सबसे अधिक अखबार हमारे यहाँ पढ़े जाते हैं, हिन्दी के संप्रेषण की यह मानवीय रचनात्मक और सारगर्भित उपलब्धि है। पत्र-पत्रिकाएँ हिदी की गुणवत्ता और प्रचार-प्रसार के लिए कृतसंकल्प है। यह भ्रम फैलाया गया था कि हिन्दी रोजगारोन्मुखी नहीं है। आज सरकारी, गैर सरकारी क्षेत्रों में करोड़ो हिन्दी पढ़े-लिखे लोग आजीविका कमा रहे हैं। भविष्य में हिन्दी की बाजार माँग और अधिक होगी।

आज कुछ बिलियमों द्वारा एक नया भ्रम फैलाया जा रहा है कि वैश्वीकरण, उत्तर-आधुनिकता एवं ज्ञान-विज्ञान से युक्त तकनीकी के दौर में हिन्दी के द्वारा समाज का विकास नहीं हो सकता इस परिप्रेक्ष्य में शोधार्थी का मत है कि हिन्दी आज घूँघट से बाहर आ चुकी है। हिन्दी का आज स्वरूप बदला है। उसका व्याकरण बदला है। उसने एक नये सौन्दर्यशास्त्र को अपनाया है, उसने विश्व को उसी की भाषा में जवाब देने के लिए, नये रूप में तैयारी की है। वरिष्ठ आलोचक शम्भूनाथ की हाँ में हाँ मिलाएँ तो - “ मैं एक ऐसा 'विश्वग्राम' देख रहा हूँ जिसमें होरी की गोशाला की जगह सुपरसोनिक विमान कनकर्ड खड़ा है। चौपाल पर डालर की दुकान है, जहाँ पान-सिगरेट भी उपलब्ध है। विश्व बैंक में झिंगुरी सिंह बैठा है। 
दुलारी सहुआइन ने सुपरबाजार खोल रखा है, जिसमें सब कुछ बिकता है। दातादीन भव्य राम मंदिर के निर्माण में लगे है और पन्द्रह मिनट की दूरी पर विज्ञान भवन में हरखू अपनी जाति का विश्व सम्मेलन कर रहा है। विश्वविद्यालय विश्व व्यापार संगठन के क्लब में बदल गए है। राय साहब ने इस बार मेडोना को बुलाया है। अब प्रहसन नहीं होता। गन्ना और मटर के खेत में आलू के चिप्स बनाये जा रहे हैं। टमाटर के एक समान पौधों पर साँस की बोतलें लटक रही है। किनारे से खडे आम के पेड़ो पर अरब देशों के छोकरे चढ़े हुए है। इंग्लैंड के प्रधानमंत्री ने वेलारी की चौड़ी सड़क पर हाथ में कुदाल लिए बेकार बैठे होरी को देखकर 'हाय' किया है और तुरंत लिबर्टी स्टैच्यू का रूख पकड़ लिया है। उस सड़क पर और सड़क से निकली सड़कों पर हूबहू होरी के चेहरे के ही करोड़ो लोग जिनमें से कुछ की जेब में कम्प्यूटर प्रशिक्षण का प्रमाण पत्र भी है अपनी नागरिकता भूलकर सन्न पड़े है। टीवी के कुछ कैमरे उन पर गिद्ध की तरह मंडरा रहे है। ${ }^{\prime \prime 4}$

इस दृष्टान्त से स्पष्ट है कि जिस तरह से आज भारतीय समाज का स्वरूप बदला है, उसकी आवश्यकताएँ बदली है उसी रूप में हिन्दी को भी स्वीकार करने की जरूरत है। विकास के लिए 'हम तो हैं परदेश में देश में निकला होगा चाँद' से निकल कर हिन्दी यदि आज “ मुन्नी बदनाम हुई डार्लिग तेरे लिए, मैं झंडू बाम हुई डार्लिंग तेरे लिए " गुनगुनाने के लिए मजबूर करती है तो बुराई क्या है? आखिर किसी न किसी की पीड़ा तो झंडूबाम दूर कर ही रहा है, क्योंकि "भूखे आदमी का सबसे बड़ा तर्क रोटी है" (धूमिल)।

उपर्युक्त विश्लेषण के आधार पर हम कह सकते हैं कि हमारी मेहनत में, प्रार्थनाओं में, सिरहानों की सिसकियों में और हमारे सपनों में जब तक हिन्दी रहेगी तब तक वह बिना किसी पीड़ा या रोग के सप्राण, सवाक् और सस्वर रहकर राष्ट्रीय विकास में अपनी भूमिका का निर्वाहन करती रहेगी।

संदर्भ-

1. पाण्डेय डॉ. पृथ्वीनाथ - 'प्रामाणिक हिन्दी- भाषा और साहित्य, शेखर प्रकाशन इलाहाबाद, संस्करण प्रथम 2007, पृष्ठ-7-8

2. देवगोड़ा एच.डी. (पूर्व प्रधानमंत्री), 14 सितम्बर 1996 हिन्दी-दिवस पर दिया गया वक्तव्य।

3. आजकल, सितम्बर 2010, प्रकाशन विभाग सूचना भवन लोदी रोड नई दिल्ली, पृष्ठ-18

4. शम्भूनाथ-'संस्कृति की उत्तरकथा', वाणी प्रकाशन नई दिल्ली, संस्करण प्रथम 2000, पृष्ठ-57 